\title{
Is bigger better? An argument for very low starting doses
}

\author{
James P. McCormack PharmD, G. Michael Allan MD, Adil S. Virani PharmD
}

$\mathrm{F}$ or years, we and others have advocated starting treatment of chronic indolent conditions at doses lower than those typically recommended in the product monographs. ${ }^{1}$ The approach we recommend is to use a very low dose when starting a new medication if the condition is not life-threatening or producing severe symptoms. Unfortunately, this approach is not used that much in practice.

First, we should define "very low dose." The "start low, go slow" approach when starting medications - which entails starting with the lowest available dose - is generally well accepted in the medical community, especially for elderly patients. However, our approach is different. We are suggesting that it is reasonable in many cases to start with half the lowest marketed dose for older, established products. For newly marketed medications, we suggest starting with half or even one-quarter the lowest available dose, because dose-response studies have either not been done or their findings have not been incorporated into the product monograph. In addition, often only one or maybe two doses are marketed initially.

Our approach has several important advantages over the use of initial doses recommended in many product monographs. The use of a very low starting dose (a) would further decrease the risk of adverse effects; (b) engage patients in determining the best dose for them; and (c) would still provide a placebo effect, if present, and mitigate the ethical issues associated with the use of placebos.

\section{Rationale}

This very-low-dose approach is based on all three pillars of evidence-based practice: evidence from clinical trials, clinical experience and patient preference.

For most conditions seen in general practice (e.g., insomnia, elevated blood pressure, mild depression, chronic obstructive lung disease, anxiety, osteoarthritis, menopausal symptoms, elevated cholesterol and elevated glucose), an immediate response to drug treatment is rarely needed.

For many marketed drugs, especially when originally launched, the recommended starting doses are too high. ${ }^{2}$ By design, initially marketed doses are ones that work for most patients. However, many of those same patients might benefit equally from lower doses. Rarely have doses on the true lower end of the dose-response curve been studied when drugs are first marketed. In a retrospective review of 354 new molecular entities available for evaluation that had been approved by the US Food and Drug Administration (FDA) between 1980 and 1999, 73 (21\%) had had a labelled dosage change; for 58 (79\%) of the 73 medications, the change was a decrease in dosage. The authors stated that "this pattern may represent a systematic flaw in premarketing dosage evaluation; it has been common practice in the pharmaceutical industry to undertake phase III trials evaluating drug effectiveness at or near maximumtolerated doses." ${ }^{\prime 3}$ Perhaps more concerning is that the need for dose adjustments has increased over time: they were three times more common during 1995-1999 than during 1980-1984.

At a minimum, a very low starting dose will yield the potential benefits such as the placebo effect and other nonspecific effects that are seen in the placebo groups of clinical trials. ${ }^{4}$ Recently, a number of authors called for the return of placebos to clinical practice, ${ }^{5}$ but this can be fraught with a number of ethical dilemmas. Using a very low dose provides a possible compromise in capturing the placebo effect yet still providing a reasonable therapeutic intervention.

Clinicians cannot reliably predict how any one patient will respond to a drug (pharmacodynamics). They can adjust for some of the pharmaco kinetic variability seen between patients by basing the dose of a medication on the patient's

\section{KEY POINTS}

- The recommended starting doses for many medications are too high for many patients.

- Unless the condition is severe or life-threatening, drug treatment can be started at a very low dose (half or one-quarter the recommended starting dose).

- Potential advantages of this approach include a further decrease in the risk of adverse events, enhanced patient participation, improved adherence and reduced long-term costs.
Competing interests:

Adil Virani receives

honoraria for educational work done in conjunction with or on behalf of the Therapeutics Initiative. He receives royalties in relation to his role as lead editor for the handbook Clinical

Handbook of Psychotropic Drugs. No competing interests declared by James McCormack or Michael Allan.

This article has been peer reviewed.

Correspondence to: Dr. James P. McCormack, jmccorma@interchange .ubc.ca

CMAJ 2011. DOI:10.1503 /cmaj.091481 
weight and renal/hepatic function; however, pharmacodynamic variability, which typically exceeds pharmacokinetic variability, ${ }^{6}$ is not really taken into account by these adjustments.

In a meta-analysis of 39 prospective studies, about three-quarters of reported side effects of medications were dose related. ${ }^{7}$ In a recent randomized controlled trial of colchicine, a dose of $1.8 \mathrm{mg}$ was found to be as effective as $4.8 \mathrm{mg}$ for the treatment of acute gout; the incidence of diarrhea was $77 \%$ (19\% severe) in the high-dose group and only $23 \%$ ( $0 \%$ severe) in the low-dose group. ${ }^{8}$

A cross-sectional study showed that patients reduced their doses to reduce their costs. ${ }^{9}$ As clinicians, we have all had patients tell us they have done the same to avoid side effects. They take their medication every other day or take half or sometimes even a quarter of the pill, and they report that it works just fine. Many patients are comfortable taking portions of tablets, and these doses frequently strike the right balance of benefit to cost and adverse events.

In animal research, in which breeding is highly controlled to the point that the animals are virtually genetically identical, there is still a wide dose-response relation. ${ }^{10}$ In the less controlled human environment, genetic and environmental variability likely leads to an even more varied dose-response effect.

\section{Are initially marketed doses too high?}

When medications are first marketed, the recommended starting doses are typically much higher than those eventually found to be effective. There appear to be a number of reasons for this predicament. ${ }^{11}$ First, health protection agencies require drug companies to show that a medication has an "effect" before it can be approved. In general, the easiest way to show an effect is to use doses that will generate a response in as many patients as possible. These doses then become the recommended dose. As Sheiner states, "The dose studied is a dose almost guaranteed to be excessive." 12

A second reason is encompassed by the natural desire to have the medication work quickly and completely. To ensure success of their product, the manufacturer would prefer as many patients as possible to have a clinical response on first use. The clinician and patient are also keen to see an immediate resolution of the clinical concern. Although this approach has definite appeal, it is not without potential complications. As noted previously, about $16 \%$ of all new products will have their doses officially decreased because of safety issues. ${ }^{3}$ Therefore, for one in every six new medications, the initially recommended starting dose is later found to be excessive and to have an unfavourable risk-benefit profile. Even for medications that do not require a later adjustment to the labelled dosage, a number of patients would benefit equally from a lower dose and a reduced risk of adverse events. These patients may be unnecessarily tolerating side effects or may stop a medication that might otherwise have been helpful without adverse events at a lower dose.

A recent example shows how organizations such as the FDA may play a role in advocating doses that are higher than necessary. Varenicline is a recently released drug for smoking cessation. Based on two comparative dosing studies of $1 \mathrm{mg}$ twice daily versus $0.5 \mathrm{mg}$ twice daily, the FDA stated that "varenicline $0.5 \mathrm{mg}$ BID appears to work as well as varenicline $1.0 \mathrm{mg}$ BID, so that subjects who cannot tolerate varenicline $1.0 \mathrm{mg}$ BID should take varenicline $0.5 \mathrm{mg}$ BID." ${ }^{13}$ If $0.5 \mathrm{mg}$ twice daily produces the same effect as $1 \mathrm{mg}$ twice daily, why is the lower dose not recommended for all patients? The right dose for a number of patients may be even lower, but by advocating doses higher than necessary for the majority of patients, the FDA has encouraged physicians to start too high.

\section{Evidence for effective lower doses}

A number of randomized controlled trials have examined the effect of lower doses (Table 1). ${ }^{8,1-25}$ Most of the studies showed no differences in effect when half or one-quarter of the usual dose, or even a smaller amount, was used. In the studies that showed a difference in response between doses, the lower doses still typically produced a clinically important response. However, these studies did not look at the effect of doses lower than those mentioned. In other words, these similarly effective lower doses likely do not reflect the lower part of the dose-response curve. Even lower doses would probably have produced a clinical response in a reasonable number of patients. So, although evidence from randomized controlled trials is helpful in showing that certain low or very low doses work, this sort of evidence is not definitively required to adopt an approach of starting with very low doses.

\section{Advantages of starting with very low doses}

One advantage is that patients would get the potential placebo effect because they know they are receiving something, albeit at a very low 
dose. This is all done without the need for deception.

Another advantage is that patients would be engaged in finding the best dose for them. Some will appreciate the concept of "just a little bit to start." Although not specifically associated with this approach to dosage, shared decision-making has been associated with improved health-related behaviours and clinical outcomes. ${ }^{26,27}$

In addition, cost savings would be considerable, as found in a retrospective review of pharmacy claims. ${ }^{28}$ For example, the use of half a tablet of a medication that normally would cost $\$ 1 /$ day amounts to more than $\$ 175$ in cost savings per year. This savings would exceed the cost associated with two or even three additional office visits that may be needed to optimize the target dose for a patient. Further cost savings may be garnered because of improved clinical outcomes owing to improved adherence to treatment regimens that are better tolerated and because of reduced adverse events.

Finally, most clinically relevant drug interactions could be avoided. Even if a patient was given a drug that led to a doubling of the concentration of the drug started at a very low dose, by using say a quarter of the normal starting dose, the increased concentration would still be well below that achieved with typical starting doses.

\section{Limitations}

The very-low-dose approach we propose does not apply to acute life-threatening conditions or when an immediate effect is desired (e.g., acute alcohol withdrawal, moderate to severe pain from osteoarthritis or reflux esophagitis, moderate to severe asthma, angina, status epilepticus), nor does it apply when the consequences of underdosing are potentially dangerous (e.g., acute bacterial infections). In these cases, it is better to err on the side of giving at least the recommended dosage immediately rather than using a slow upward titration. In addition, the verylow-dose approach (other than the initial titration) cannot be used in conditions for which a therapeutic effect or outcome cannot easily be determined (e.g., reduction in the frequency of seizures in a patient who has seizures only once or twice a year).

For some situations, such as the use of angiotension-converting-enzyme (ACE) inhibitors in patients with heart failure, guidelines recommend starting treatment at target doses. However, the main evidence showing a difference in outcome between a high-dose and a low-dose ACE inhibitor for heart failure came from a randomized controlled trial in which the high dose was 7 to 14 times higher than the low-dose comparator. ${ }^{29}$ Although we are not recommending lower doses as a target, this serves as an example of how some dosing studies without mid-dose options create uncertainty: Would half or one-quarter the high dose be as effective as the high dose? We do not know because these lower doses were not studied. Regardless, there are potential advantages to starting with a low dose and working upward from there, to reduce the risk of side effects. In addition, if patients can tolerate half or one-quarter the target dose, that is likely better than abandoning the drug completely.

Undoubtedly some patients will end up requiring higher doses. In these patients, the strategy of starting with a very low dose could result in some delay or inconvenience; this is a counterbalance to the cost savings and reduced risks of adverse events for all patients as well as

Table 1: Examples of the effect of lower doses reported in randomized controlled trials*

\begin{tabular}{|c|c|c|}
\hline Medication & $\begin{array}{l}\text { Lower dose } \\
\text { studied }\end{array}$ & Result \\
\hline Hydrochlorothiazide & $6.25 \mathrm{mg} / \mathrm{d}$ & $\begin{array}{l}\text { Effective at lowering blood pressure; } \\
\text { first marketed at } 50 \text { to } 200 \mathrm{mg} / \mathrm{d}^{14}\end{array}$ \\
\hline Captopril & $6.25 \mathrm{mg}$ & $\begin{array}{l}\text { Effective at lowering blood pressure } \\
\text { as a single dose and when given twice } \\
\text { daily over a longer term; captopril } \\
25 \mathrm{mg} \text { three times daily is still } \\
\text { commonly recommended as a starting } \\
\text { dose for hypertension }{ }^{15}\end{array}$ \\
\hline Sildenafil & $25 \mathrm{mg}$ & $\begin{array}{l}\text { As effective as } 50-100 \mathrm{mg} \text { for erectile } \\
\text { dysfunction }^{16}\end{array}$ \\
\hline Sumatriptan & $25 \mathrm{mg}$ & $\begin{array}{l}\text { Virtually as effective as } 100 \text { mg; most } \\
\text { drugs in this class have a flat dose- } \\
\text { response curve at the doses studied }{ }^{17}\end{array}$ \\
\hline Fluoxetine & $5 \mathrm{mg} / \mathrm{d}$ & $\begin{array}{l}\text { Effects at this dose were similar to } \\
\text { those at } 20 \mathrm{mg} / \mathrm{d} \text { and } 40 \mathrm{mg} / \mathrm{d}^{18}\end{array}$ \\
\hline Ezetimibe & $0.25 \mathrm{mg}$ & $\begin{array}{l}\text { 1/40th of the recommended starting } \\
\text { dose of } 10 \text { mg provided } 50 \% \text { of the } \\
\text { effect of lowering low-density } \\
\text { lipoprotein levels achieved with } 10 \mathrm{mg}^{19}\end{array}$ \\
\hline Elemental iron & $15 \mathrm{mg} / \mathrm{d}$ & $\begin{array}{l}\text { As effective as } 50 \mathrm{mg} \text { and } 150 \mathrm{mg} \text { for } \\
\text { treating anemia in elderly patients, } \\
\text { with fewer side effects }\end{array}$ \\
\hline Bupropion & $150 \mathrm{mg} / \mathrm{d}$ & $\begin{array}{l}\text { Rate of smoking cessation at one year } \\
\text { was the same as that with } 300 \mathrm{mg} / \mathrm{d}^{21}\end{array}$ \\
\hline Atorvastatin & $10 \mathrm{mg}$ & $\begin{array}{l}\text { Produced two-thirds the effect on } \\
\text { cholesterol as that with } 80 \mathrm{mg}^{22}\end{array}$ \\
\hline Ibuprofen & $200 \mathrm{mg}$ & $\begin{array}{l}\text { As effective as } 400 \mathrm{mg} \text { for migraine } \\
\text { headache }^{23}\end{array}$ \\
\hline Ranitidine & $25 \mathrm{mg}$ & $\begin{array}{l}\text { As effective as } 125 \mathrm{mg} \text { for heartburn } \\
\text { relief }^{24,25}\end{array}$ \\
\hline Colchicine & $1.8 \mathrm{mg}$ & $\begin{array}{l}\text { As effective as } 4.8 \mathrm{mg} \text { for acute gout, } \\
\text { with fewer adverse events }{ }^{8}\end{array}$ \\
\hline
\end{tabular}


the clear advantage for patients requiring only the lowest doses. A very-low-dose approach is not meant to be dogmatic. Clinicians and patients should discuss the right starting dose based on the patient's individual characteristics and history.

Starting with a very low dose may add some complexity to treatment initiation and take more time both in developing a treatment plan with the patient and reaching the best dose for the patient. During titration, some patients (and perhaps clinicians) may lose patience with the process and assume the medication is ineffective after only a few dose increases. Clinicians need to educate patients about how the best dose for them may be higher than the starting dose and that it may take a few increases to find the right dose. For some patients, our proposed strategy will take time, particularly as titration plans are developed and clarified, but we feel that the time will not exceed that spent in normal, informed decision-making. As well, time spent reaching the right dose may result in increased adherence and may reduce the time spent dealing with the consequences of toohigh doses or stopped medications.

Another limitation is that, although most side effects are dose-related, some of the more serious life-threatening idiosyncratic allergic reactions are often not dose-related and could still occur despite starting with very low doses.

Finally, given that "side effects" are reported in placebo groups of clinical trials, patients receiving very low starting doses may still report side effects that may or may not be caused by the drug.

\section{Practical suggestions}

A discussion with the patient about the rationale and approach to starting drug treatment at a very low dose is essential. Clinicians should explain how individuals respond differently to different doses and determine whether the patient prefers to start at a lower or higher dose, after discussing the benefits and limits of each. When starting with a very low dose, patients should be advised that they may not respond immediately and that, with upward titration, the right dose that improves the condition while minimizing the risk of dose-related adverse events will be found.

Not all drugs come in forms that allow small doses to be used. However, the majority of tablets can be split, especially with a pill cutter. Although splitting tablets does not always result in perfect sized pieces, ${ }^{30}$ patients need not be too concerned if every piece is not exactly the same size, even for drugs with a low therapeutic index.
Some capsules can be opened and the dose reduced that way. Alternatively, the interval between doses could be increased; for example, a proton pump inhibitor could be taken every two to three days instead of daily. Finally, a number of drugs come in liquid form; for example, fluoxetine is available as a liquid ( $20 \mathrm{mg}$ per $5 \mathrm{~mL}$ ).

\section{Conclusion}

For most conditions that are not life-threatening or severe, there are few legitimate reasons not to start with a very low dose and titrate upward. Dose titration will likely improve tolerability, may improve adherence if side effects are reduced, and will reduce drug costs if a low or very low dose is found to be effective. An alternative approach to determining the best dose for a patient is to start with a higher dose, get a response and then reduce the dose to the lowest effective dose. Some patients may prefer this approach, but it increases the risk of dose-related side effects, and both the clinician and the patient may be reluctant to decrease the dose once an effect has been achieved.

\section{References}

1. Therapeutics Initiative. Dose titration: minimize to maximize. Therapeutics Letter 1995;10. Available: www.ti.ubc.ca/node/90 (accessed 2010 Sept. 3)

2. Cohen JS. Over dose: the case against the drug companies. New York (NY): Tarcher/Putnam; 2001.

3. Cross J, Lee H, Westenlinck A, et al. Postmarketing drug dosage changes of 499 FDA-approved new molecular entities, 1980 1999. Pharmacoepidemiol Drug Saf 2002;11:439-46.

4. Hróbjartsson A, Gøtzsche PC. Placebo interventions for all clinical conditions [review]. Cochrane Database Syst Rev 2004;(3): CD003974.

5. Pittrof R, Rubenstein I. The thinking doctor's guide to placebos. BMJ 2008;336:1020.

6. Levy G. Predicting effective drug concentrations for individual patients. Determinants of pharmacodynamic variability. Clin Pharmacokinet 1998;34:323-33.

7. Lazarou J, Pomeranz BH, Corey PN. Incidence of adverse drug reactions in hospitalized patients: a meta-analysis of prospective studies. JAMA 1998;279:1200-5.

8. Terkeltaub RA, Furst DE, Bennett K, et al. High versus low dosing of oral colchicine for early acute gout flare: twenty-fourhour outcome of the first multicenter, randomized, double-blind, placebo-controlled, parallel-group, dose-comparison colchicine study. Arthritis Rheum 2010;62:1060-8.

9. Tseng CW, Brook RH, Keeler E, et al. Cost-lowering strategies used by Medicare beneficiaries who exceed drug benefit caps and have a gap in drug coverage. JAMA 2004;292:952-60.

10. Craig CR, Shideman FE. Metabolism and anticonvulsant properties of mephobarbital and phenobarbital in rats. $J$ Pharmacol Exp Ther 1971;176:35-41.

11. Cohen JS. Dose discrepancies between the physicians' desk reference and the medical literature, and their possible role in the high incidence of dose-related adverse drug events. Arch Intern Med 2001;161:957-64.

12. Sheiner LB. The intellectual health of clinical drug evaluation. Clin Pharmacol Ther 1991;50:4-9.

13. Statistical review and evaluation: clinical studies - Chantix (varenicline tartrate). Rockville (MD): Center for Drug Evaluation and Research, Department of Health and Human Services, US Food and Drug Administration; 2005.

14. Frishman WH, Bryzinski BS, Coulson LR, et al. A multifactorial trial design to assess combination therapy in hypertension. Treatment with bisoprolol and hydrochlorothiazide. Arch Intern Med 1994;154:1461-8. 
15. Thind GS, Mahapatra RK, Johnson A, et al. Low-dose captopril titration in patients with moderate-to-severe hypertension treated with diuretics. Circulation 1983;67:1340-6.

16. Goldstein I, Lue TF, Padma-Nathan H, et al.; Sildenafil Study Group. Oral sildenafil in the treatment of erectile dysfunction. N Engl J Med 1998;338:1397-404.

17. Ferrari MD, Goadsby PJ, Roon KI, et al. Triptans (serotonin, 5-HT1B/1D agonists) in migraine: detailed results and methods of a meta-analysis of 53 trials. Cephalalgia 2002;22:633-58.

18. Gram L. Fluoxetine. N Engl J Med 1994;331:1354-61.

19. Bays HE, Moore PB, Drehobl MA, et al. Effectiveness and tolerability of ezetimibe in patients with primary hypercholesterolemia: pooled analysis of two phase II studies. Clin Ther 2001;23:1209-30

20. Rimon E, Kagansky N, Kagansky M, et al. Are we giving too much iron? Low-dose iron therapy is effective in octogenarians. Am J Med 2005;118:1142-7.

21. Hurt RD, Sachs DP, Glover ED, et al. A comparison of sustained-release bupropion and placebo for smoking cessation. N Engl J Med 1997;337:1195-202.

22. Nicholls SJ, Brandrup-Wognsen G, Palmer M, et al. Meta-analysis of comparative efficacy of increasing dose of atorvastatin versus rosuvastatin versus simvastatin on lowering levels of atherogenic lipids (from VOYAGER). Am J Cardiol 2010;105:69-76.

23. Codispoti JR, Prior MJ, Fu M, et al. Efficacy of nonprescription doses of ibuprofen for treating migraine headache. A randomized controlled trial. Headache 2001;41:665-79.

24. Pappa KA, Buaron K, Payne JE, et al. An evaluation of increasing doses of ranitidine for treatment of heartburn. Aliment Pharmacol Ther 1999;13:475-81.

25. Pappa KA, Gooch WM, Buaron K, et al. Low-dose ranitidine for the relief of heartburn. Aliment Pharmacol Ther 1999;13: 459-65.

26. Kaptchuk TJ, Kelley JM, Conboy LA, et al. Components of placebo effect: randomised controlled trial in patients with irritable bowel syndrome. BMJ 2008;336:999-1003.

27. Heisler M, Bouknight RR, Hayward RA, et al. The relative importance of physician communication, participatory decision making, and patient understanding in diabetes self-management. J Gen Intern Med 2002;17:243-52.

28. Stafford RS, Radley DC. The potential of pill splitting to achieve cost savings. Am J Manag Care 2002;8:706-12.

29. Packer M, Poole-Wilson PA, Armstrong PW, et al. Comparative effects of low and high doses of the angiotensin-converting enzyme inhibitor, lisinopril, on morbidity and mortality in chronic heart failure. ATLAS Study Group. Circulation 1999; 100:2312-8.

30. Teng J, Song CK, Williams RL, et al. Lack of medication dose uniformity in commonly split tablets. J Am Pharm Assoc (Wash) 2002;42:195-9.

Affiliations: From the Faculty of Pharmaceutical Sciences (McCormack, Virani), University of British Columbia, Vancouver BC; the Faculty of Medicine (Allan), University of Alberta, and the Toward Optimized Practice program (Allan), Edmonton, Alta; and the Fraser Health Authority (Virani), Surrey, BC

Contributors: All of the authors contributed substantially to the conception and design of the article. James McCormack drafted the article; all of the authors revised it critically for important intellectual content and approved the final version.

Acknowledgement: The concept for this paper was inspired by Dr. Robert Rangno, who regularly provided us with a "high dose" of his clinical experience with very low doses.

\section{S SECUREGARD ${ }^{\oplus}$ Single-use, Retractable Safety} Syringes are now available in Canada!

With "Re-use Prevention Features" as required by the World Health Organization and UNICEF!

A cost-effective solution to meet injection safety requirements. Available in 1,3 and $5 \mathrm{~mL}$ sizes.

CALL NOW FOR PRICING AND AVAILABILITY

$$
1-800-998-8251
$$

For a complete list of configurations and availability, please visit our website at WWW.responsescientific.ca
Response Scientific Canada Inc. 107-50 Ottawa Street South Kitchener, Ontario N2G 3S7 